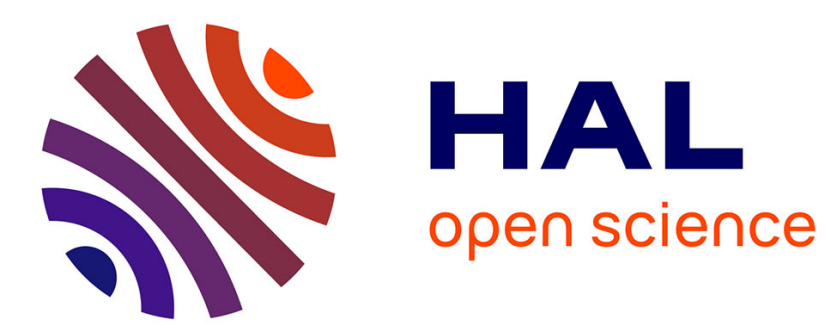

\title{
INELASTIC NEUTRON SCATTERING OF WATER AND ICE IN POROUS SOLIDS
}

\author{
J. Ramsay, H. Lauter, J. Tompkinson
}

\section{To cite this version:}

J. Ramsay, H. Lauter, J. Tompkinson. INELASTIC NEUTRON SCATTERING OF WATER AND ICE IN POROUS SOLIDS. Journal de Physique Colloques, 1984, 45 (C7), pp.C7-73-C7-79. 10.1051/jphyscol:1984707 . jpa-00224268

\section{HAL Id: jpa-00224268 https://hal.science/jpa-00224268}

Submitted on 1 Jan 1984

HAL is a multi-disciplinary open access archive for the deposit and dissemination of scientific research documents, whether they are published or not. The documents may come from teaching and research institutions in France or abroad, or from public or private research centers.
L'archive ouverte pluridisciplinaire HAL, est destinée au dépôt et à la diffusion de documents scientifiques de niveau recherche, publiés ou non, émanant des établissements d'enseignement et de recherche français ou étrangers, des laboratoires publics ou privés. 


\author{
J.D.F. Ramsay, H.J. Lauter ${ }^{\star}$ and J. Tompkinson ${ }^{\star}$ \\ Chemistry Division, AERE, Harwel2, Oxfordshire OX11 ORA, U.K. \\ Institut Max von Laue-Paul Langevin, 38042 Grenobie, France
}

\begin{abstract}
Résumé - L'arrangement intermoléculaire de $1^{\prime}$ eau à $80 \mathrm{~K}$ dans les gels de titane, les zểolites et le chlorhydrate d'alumine a été étudié par la diffusion inélastique des neutrons. Les mesures effectuées de 35 jusqu'à $250 \mathrm{meV}$, comprennent les fréquences des libration et déformation des molécules. Les spectres ont mis en évidence des différences avec la glace qui augmentent quand la taille des pores de $1^{\prime}$ adsorbat diminue. Ces effets sont attribués à une structure de l'eau moins organisêe que celle de la glace et dans laquelle les liaisons hydrogène sont moins nombreuses.
\end{abstract}

Abstract - The intermolecular structure of sorbed water and its dependence on the surface and porous properties of the adsorbent has been studied by Incoherent Inelastic neutron scattering measurements of water at $80 \mathrm{~K}$ in titania gels, Zeolite-A and aluminium chlorohydrate. An energy transfer range from $\sim 35$ to $\sim 250$ meV was covered which included the frequences of molecular librations and deformation mode. Spectra showed an increasing departure from that of bulk ice as the pore size and water uptake was reduced. These changes can be tentatively ascribed to a less ordered water structure where hydrogen bonding is restricted compared to that in bulk ice.

\title{
1 - INTRODUCTION
}

There is considerable evidence which suggests that the properties of water close to solid interfaces are significantly different from those in the bulk /1,2/. However the range of influence of interfaces on water structure still remains controversial. Structural studies of water within porous materials may provide an important insight into this problem, as has been demonstrated by recent neutron diffraction measurements of $\mathrm{D}_{2} 0$ within porous silicas /3/. From these it was concluded that there was no appreciable structural modification in the liquid but at low temperature there was evidence of structural disorder and the formation of cubic ice, rather than the normal hexagonal ice. Changes in the structure of water are also reflected in the intermolecular vibrational spectra, particularly the librational bands which are very sensitive to variations in hydrogen bonding. This has been demonstrated by several investigations $/ 4,5,6 /$ of bulk ice and water, using mainly infra red and Raman spectroscopy, which have been related to structura1 predictions based on computer simulation $/ 7,8 /$. For the study of water in porous materials however, inelastic neutron scattering (INS) has a particular advantage, because apart from the absence of selection rules, the incoherent cross-section of the H-atom is considerably larger than that of other atoms. This feature is demonstrated in the present INS investigation of ice and water adsorbed at low temperature in well characterised porous titania gels and zeolites.

\section{2 - VIBRATIONAL SPECTRA OF LIOUID WATER AND ICE}

Vibrational spectra of water and ice have been determined extensively by infra red $14,9 /$ and Raman spectroscopy $/ 6,10,11 /$, although neutron scattering measurements 
have been much less numerous. The frequencies of the three intramolecular modes corresponding to the $v_{1}$ symmetric vibration-active in the Raman and inactive in the infra red, the deformation mode (scissors vibration), $v_{2}$, and the $v_{3}$ antisymmetric vibration - active in the infra red and inactive in the Raman are shown in Table 1. only one of these, the $v_{2}$ vibration, falls within the range of energy transfer covered in the present study. Bands of lower frequency arise from intermolecular vibrations corresponding to librational and translational motions. The frequencies of these, which are sensitive to hydrogen bonding and the structure of ice and liquid water (they are absent in the vapour), are less well defined and the approximate ranges as determined by Raman spectroscopy /6,11/ are shown in Table 1 .

Table 1

Spectral frequencies (meV) of ice and water determined from i.r. and Raman Spectroscopy

\begin{tabular}{|c|c|c|c|c|c|c|}
\hline & $v_{3}$ & $v_{1}$ & $v_{2}$ & $2 v_{\mathrm{L}}$ & $v_{\mathrm{L}}$ & $v_{\mathrm{T}}$ \\
\hline water & 433 & 407 & 204 & & $92-89,68,56-53$ & $22-7$ \\
\hline ice I & 399 & 384 & 205 & $179,136,128 *$ & $113,93,75 *$ & $\sim 35-5$ \\
\hline
\end{tabular}

* Values from Raman measurements at $269 \mathrm{~K} / 6 /$; at $123 \mathrm{~K} 2 \nu_{\mathrm{L}}$ and $v_{\mathrm{L}}$ increased by $\sim 8$ and $4 \mathrm{meV}$ respectively. N.B. $100 \mathrm{meV} \approx 806 \mathrm{~cm}^{-1}$

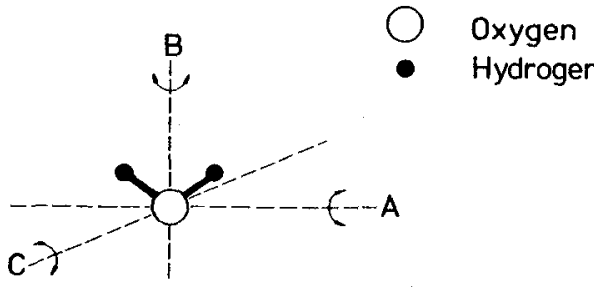

Fig. 1 - Librational modes of water about the three principal axes of the molecule.

The 1ibrational motions of water about the three principal axes of an isolated molecule are shown in Fig. 1. These are referred to as the wagging, twisting and rocking vibrations respectively, and only two of these (about the $A$ and $C$ axes) are active in the i.r. and Raman. All three librations should be observed by neutron scattering and should increase in frequency in the same order as the reciprocal of the respective moments of inertia about the axes: $I_{C}^{-1}<I_{B}^{-1}<I_{A}^{-1}$ In bulk water and ice there is strong molecular coupling due to H-bonding forces, and the 3 librations of one uncoupled molecule will tend to give a broad band of frequencies. These will have a higher frequency in ice compared to water because of the more extensive hydrogen bonding, as has been observed (Table 1). Moreover in ice, which has a structure with four H-bonds per molecule (c.f. Ice $I_{h}$ ), compared to the disorded $\mathrm{H}^{-}$ bonded structure of liquid water, there will be more possibility that the Erequencies of the separate librations will be resolvable. 


\section{3 - EXPERIMENTAL}

\subsection{Materials}

Titanias having different surface and porous properties (Table 2) were prepared as follows: hydrous titanium oxide (HTO) was precipitated from a solution of titanium chloride with sodium hydroxide. The wet sample was filtered as a paste (containing exchangeable $\mathrm{Na}^{+}$ions; this was dried slowly (at $\sim 295 \mathrm{~K}$ and eventually at $\sim 350 \mathrm{~K}$ ) samples containing different water contents being removed progressively. A similar procedure was used to prepare deuterated samples and also those containing $\mathrm{Cs}^{+}$and $\mathrm{Li}^{+}$as exchangeable cations. Mesoporous titanias I and II were prepared $/ 12 /$ by drying two different sols (containing primary particles of anatase having different sizes) to give hard glassy gels. Properties - table 2 were determined from measurements of $\mathrm{N}_{2}$ adsorption isotherms at $77 \mathrm{~K}$ made on samples outgassed at $\sim 295 \mathrm{~K}$.

Table 2

Properties of porous titanias

\begin{tabular}{|c|c|c|c|c|}
\hline Titania & $\begin{array}{c}\text { Specific surface * } \\
\text { area, } \mathrm{S}_{\mathrm{BET}} / \mathrm{m}^{2} \mathrm{~g}^{-1}\end{array}$ & $\begin{array}{c}\text { Total pore * } \\
\text { volume, } \mathrm{v}_{\mathrm{p}}, \mathrm{cm}^{3} \mathrm{~g}^{-1}\end{array}$ & $\begin{array}{c}\text { Mean pore * } \\
\text { diameter, } \mathrm{d}_{\mathrm{p}} / \mathrm{nm}\end{array}$ & $\begin{array}{c}\text { Structure } \\
(\mathrm{XRD})\end{array}$ \\
\hline $\begin{array}{c}\text { Hydrous titanium } \\
\text { oxide (HTO) } \\
\text { microporous }\end{array}$ & 262 & 0.15 & 62 & amorphous \\
\hline $\begin{array}{c}\text { Mesoporous } \\
\text { titania I }\end{array}$ & 221 & 0.33 & 6.5 & $\begin{array}{l}\text { poorly } \\
\text { crystalline } \\
\text { anatase }\end{array}$ \\
\hline $\begin{array}{l}\text { Mesoporous } \\
\text { titania II }\end{array}$ & 54 & 0.43 & 34 & anatase \\
\hline
\end{tabular}

* per $g$ of hydrated titania - after slow drying in air at $~ 295 \mathrm{~K}$

+ Results for typical sample washed free of $\mathrm{Na}^{+}$ions and dried in air.

Samples of Zeolite 5A (containing exchangeable $\mathrm{Ca}^{2+}$ ) were obtained from the Linde Corp; these were saturated with water $\left(\sim 0.3 \mathrm{~g} \mathrm{~g}^{-1}\right)$ by exposing at the SVP in a dessicator. $\mathrm{Ca}^{2+}$ was enchanged for $\mathrm{Li}^{+}$and $\mathrm{Cs}^{+}$by immersing the zeolite several times in solutions of $\mathrm{LiNO}_{3}$ and $\mathrm{CsNO}_{3}\left(2 \mathrm{~mol} \mathrm{dm}^{-3}\right)$.

Aluminium chlorohydrate (ACH) was prepared as a transparent glassy solid by partially drying a commercial (Hoechst) ACH solution which has been studied previously /13/. The amorphous glassy hydrate has the probable constitution $\left[\mathrm{Al}_{13} \mathrm{O}_{4}(\mathrm{OH})_{24}\left(\mathrm{H}_{2} \mathrm{O}\right)_{12}\right] \mathrm{Cl}_{7}$.

\subsection{Neutron scattering}

Inelastic neutron scattering measurements were made with the INIB beryllium filter spectrometer /14/ installed on the hot source of the HFR at ILL, Grenoble. Differential incoherent cross sections were determined by scanning the incident neutron energy; a range from 35 to $\sim 250 \mathrm{meV}$ was covered using successively the (111), (002) and (220) Bragg reflections of the copper monochromator. The resolution function (FWHM) increased from $\sim 3$ to 10 and 8 to 35 meV over the ranges covered by the $(002)$ and $(220)$ planes respectively /15/. Samples, contained in thin rectangular aluminium sachets, had a thickness which was calculated to give a total scattering cross section of approximately $10 \%$. The scattering angle at the sample was $40^{\circ}$. Measurements were made at $\sim 80 \mathrm{~K}$ (1iquid nitrogen cryostat), although in one experiment the sample was varied between $10 \mathrm{~K}$ and $300 \mathrm{~K}$ using a Displex cryostat. 
The INS spectrum of ice (Fig. 2a) at $\sim 80 \mathrm{~K}$ shows a librational band, extending from $\sim 65 \mathrm{meV}$ to $130 \mathrm{meV}$, with peaks at $81 \mathrm{meV}$ and $\sim 102 \mathrm{meV}$. There is also evidence (220 plane) of a shoulder at $\sim 110 \mathrm{meV}$. A broad weaker band extends from $\sim 150$ to $240 \mathrm{meV}$ with a maximum $\sim 200 \mathrm{meV}$. The librational band can be synthesised by convoluting three Gaussians (centred at 78,96 and $116 \mathrm{meV}$ ) as shown. The synthesis showing bands of low intensity in the range $150-180 \mathrm{meV}$, followed by a maximum at $207 \mathrm{meV}$ may tentatively be ascribed to librational overtones and the $v_{2}$ deformation respectively. These frequencies are in very good accord with similar assignments derived from recent Raman measurements (Table 1) /6/.

The spectrum of sorbed water in Zeolite 5A at $80 \mathrm{~K}$ (Fig. 2b) shows several different features compared to bulk ice: the librational band now has no well defined maxima, and has broadened by shifting to lower frequency, extending from 45 to $\sim 120 \mathrm{meV}$. The broad librational overtone band has now almost disappeared and the $\nu_{2}$ band at $\sim 210 \mathrm{meV}$, has a reduced intensity. Measurements made on the $\mathrm{Li}^{+}$and $\mathrm{Cs}^{+}{ }^{2}$ exchanged forms of Zeolite A containing water saturating the intracrystalline pore volume, showed very similar features.

The changes in the libration band suggest that the water in the zeolite cavities has a more disordered structure compared to that of bulk ice, in which the number of $\mathrm{H}^{-}$ bonds may be variable with an average somewhat less than the four per molecule in hexagonal ice. Thus, molecular dynamics simulations of the structure of liquid water made by Stillinger /16/, indicate that the number of H-bonds per molecule has a broad distribution with a mean of 2.3 ; this would likewise accord with the broader libration band observed at even lower frequency for the liquid (Table 1). Disorder may arise in the zeolite cavities because of the effect of interactions between the water molecules and the alumino silicate framework. Since at saturation there are only $\sim 27$ molecules per cavity in CaA, the development of the long range order found in ice would be prevented.

In solid aluminium chlorhydrate (ACH) the librational band (Fig. $2 \mathrm{c}$ ) occurs at a slightly lower frequency than observed for CaA, but again shows rore distinct features (maxima at $70,76 \mathrm{meV}$ and shoulders at $104,120,141 \mathrm{meV}$ ) as observed in bulk ice. This would suggest that the hydrogen bonding and co-ordination of water in the hydrate was sufficiently regular although less extensive than in ice, to give rise to discrete librational modes. Although a detailed interpretation is not possible here the present results are consistent with several studies of librational modes in simpler salt crystals $/ 17,18 /$ from which details of the environment and potential field of water molecules has been derived.

\subsection{Porous titanias}

Spectra of sorbed water (at $80 \mathrm{~K}$ ) in titanias (Fig. $3 a, 3 b$ and $3 \mathrm{c}$ ) containing pores of different sizes (Table 2) clearly illustrate the effect of the cluster size on the intermolecular structure of water, which has been referred to with Zeolite A. Thus the sorbed water $\left(0.24 \mathrm{~g} \mathrm{~g}^{-1}\right)$ within the titania having the largest pores has a librational spectrum (3a) which is very similar to bulk ice. The additional shoulder at $58 \mathrm{meV}$ however suggests the presence of some disordered water which may arise close to the titania surface.

Within the smaller pores of the mesoporous titania $\mathrm{I}$, the water $\left(0.26 \mathrm{~g} \mathrm{~g}^{-1}\right) \mathrm{has}^{\mathrm{l}}$ less ordered structure, as evidenced by the broad 1fbrational band ( 3 b), having similar features to that observed with Zeolite A. Since the pores in the gel are formed by a packing of the approximately spherical particles of anatase /12/, thus giving a structure containing interconnected cavities, it is possible to make a. crude estimate of the number of water molecules which would saturate an "individual" pore. (N.B. Fig. 3b corresponds to $\sim 75 \%$ of total saturation). Assuming these pores are spheroidal, with a diameter of $6.5 \mathrm{~nm}$, this would correspond to a cluster containing $\sim 4 \times 10^{3}$ molecules. 


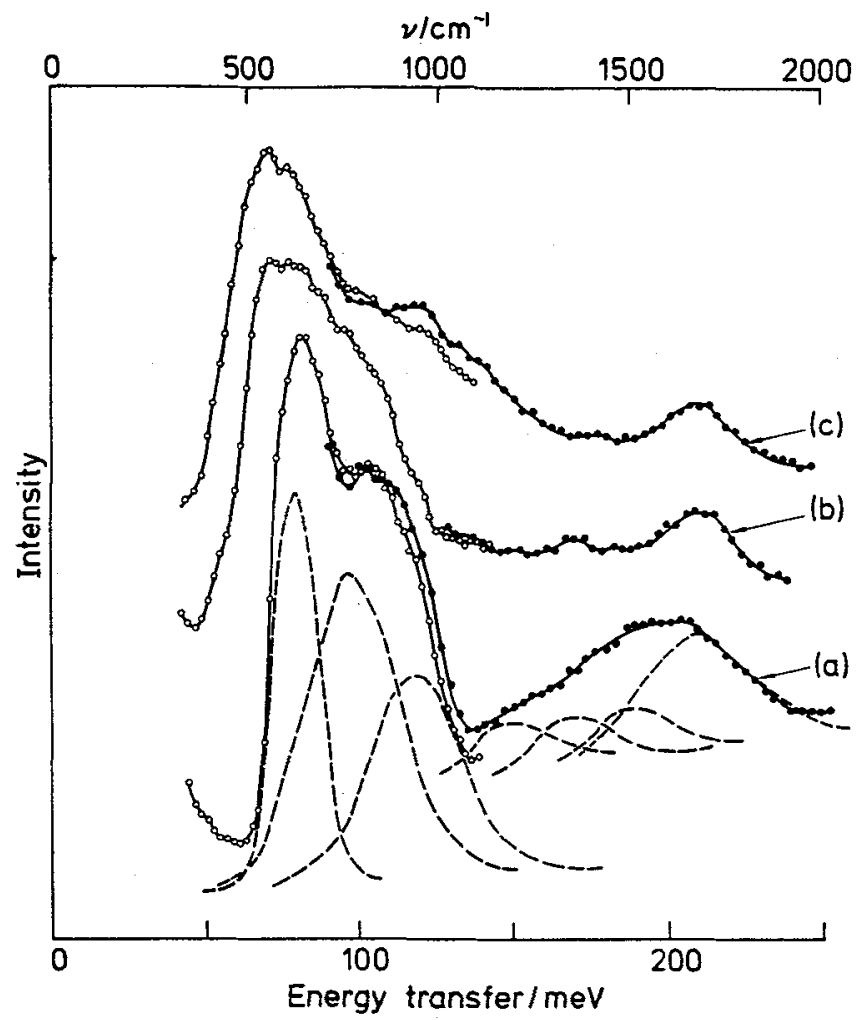

Fig. 2 - Inelastic neutron scattering spectra of water at $80 \mathrm{~K}$ (a) ice (b) in zeolite-A (c) in aluminium chlorohydrate. Broken lines are Gaussians which when synthesised give the experimentally determined spectrum of ice in (a). open and closed symbols denote measurements with the $\mathrm{Cu}(002)$ and (220) monochromator planes respectively.

The pores within the microporous titania are considerably smaller and are of the order of molecular size as is evident from the type $I$ adsorption isotherm obtained with $\mathrm{N}_{2}$ at $77 \mathrm{~K}$. Although further discussion is not appropriate here, it is probable that $\mathrm{N}_{2}$ is only partially accessible to the structure due to the small size of the pores, and strong retention of water even after pumping. For this reason the values of $\mathrm{S}_{\mathrm{BET}}$ and $\mathrm{v}_{\mathrm{p}}$ quoted in Table 2 are likely to be underestimates; furthermore the value of $d_{0}$, although small, cannot be determined precisely from a type $I$ isotherm /19/. Fig. 3c shows the librational band of a gel sample containing a typically high water content (35\% weight loss on ignition). Although it is evident that the librational band is broadened and shifted to lower frequency ( $45 \mathrm{meV})$, there is a distinct maximum at $70 \mathrm{meV}$ (lower than in ice). The latter may indicate that the water molecules are less hydrogen bonded, but nevertheless have a more ordered structure than in mesoporous titania $I$ and zeolite $A$, which is perhaps more akin to the co-ordinated water in $\mathrm{ACH}$. Such a structure might arise from the extensive coordination of water molecules with the hydroxylated titania surface, which could occur in micropores.

The possible influence of the titania surface on the water structure can also be seen in Fig. 4, which shows librational bands of HTO at progressive stages of dehydration. For a thick paste $\left(26 \% \mathrm{w} / \mathrm{w}\right.$ as $\mathrm{TiO}_{2}$ ) the band (4a) is very similar to that of ice although there is an additional shoulder at $\sim 65 \mathrm{meV}-$ possibly due to water near the surface of the small $(\leqslant 4 \mathrm{~nm})$ amorphous particles. In the almost 


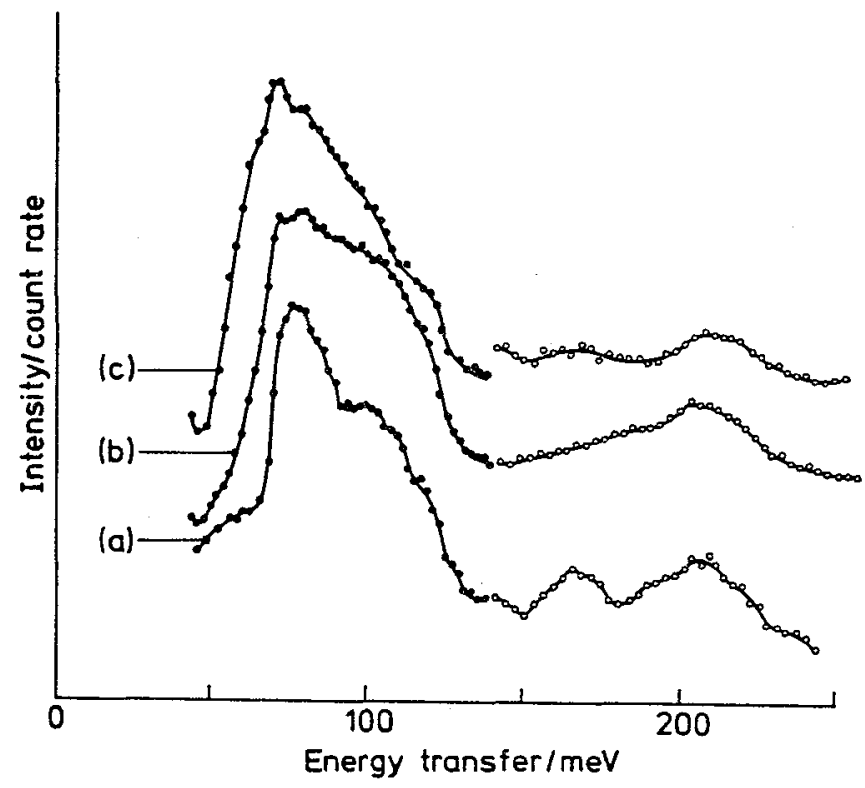

Fig. 3 - INS spectra of water at $80 \mathrm{~K}$ in porous titanial gels; (a) and (b), mesoporous titanias $I$ and II, (c) microporous HTO.

solid gel, containing a lower water content (55\% $\mathrm{w} / \mathrm{w}$ as $\left.\mathrm{TiO}_{2}\right)$, this band is much more evident ( $4 \mathrm{~b}$ ) until on further dehydration ( $76 \% \mathrm{w} / \mathrm{w}$ as $\mathrm{TiO}_{2}$ ) a broader band shifted to lower energy, is observed ( $4 \mathrm{c})$.

Sampies containing $\mathrm{Cs}^{+}$and $\mathrm{Li}^{+}$ions, had similar librational spectra to that described for the HTO containing exchangeable $\mathrm{Na}^{+}$ions, which would suggest that the pore size and titania surface have a more dominant effect on the intermolecular structure of water than the charge density of the cation. The effects of deuterium substitution on the librational band in one HTO preparation ( $65 \% \mathrm{w} / \mathrm{w} \mathrm{TiO}$ ) were also investigated. The band was shifted to lower energy, with a maximum at $\sim 55 \mathrm{meV}$, and extended down to $\sim 35 \mathrm{meV}$; a small maximum, at $\sim 154 \mathrm{mey}$, corresponded to the $v_{2}$ vibration. These shifts have a ratio very close to $2^{\frac{1}{2}}$, as is expected for modes involving mainly motions of hydrogen atoms.

In one experiment librational bands of water in HTO $\left(65 \% \mathrm{w} / \mathrm{w}\right.$ TiO $\left.{ }_{2}\right)$ were measured at increasing temperatures $(10,45,200$ and $300 \mathrm{~K})$ extending above the melting point of bulk ice. Although band broadening occurred with increases in temperature, the position of the peak maximum remained almost unchanged, indicating an absence of a distinct phase transition. This would suggest that the effects of the force fields within the HTO micropores dominate the structure of water, and result in a more extensive $\mathrm{H}$-bonded arrangement of the molecules above $273 \mathrm{~K}$, possibly by restricting librational and translation motion.

\section{5 - CONCLUSION}

Measurements of librational spectra of water adsorbed at $80 \mathrm{~K}$ in porous titanias and zeolite $A$ indicate the structure is more disordered and less extensively hydrogen bonded than in bulk ice at similar temperature. These effects become more marked as the pore size is decreased and the water uptake is reduced. Tentative estimates of the adsorbed layer thickness in small mesopores show that disorder may extend out to beyond $\sim 1.2 \mathrm{~nm}$ from the titania surface but such effects are minimal in larger mesopores where the thickness is $\gtrsim 4 \mathrm{~nm}$. 


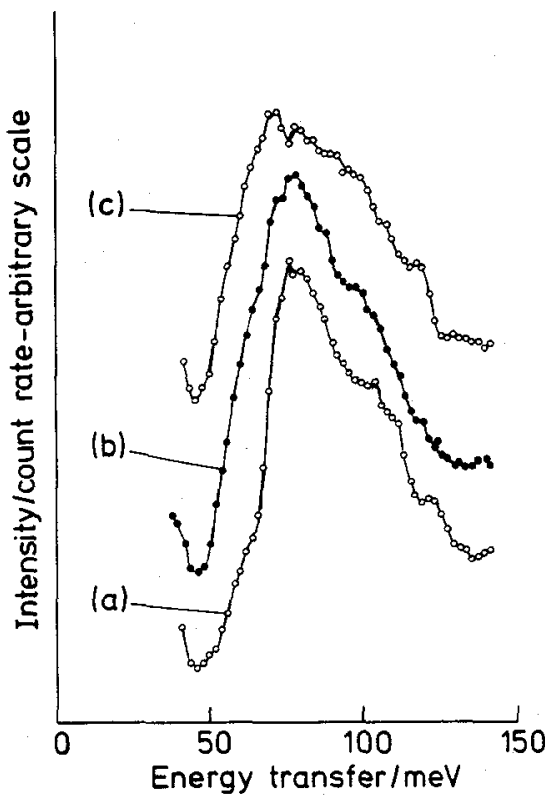

Fig. 4 - INS spectra of water at $80 \mathrm{~K}$ in HTO preparations at progressfve stages of dehydration. Percentages, $\mathrm{w} / \mathrm{w}$ of $\mathrm{TiO}_{2}$, are (a) 26 (b) 55 and (c) 76 respectively.

\section{ACKNOWLEDGEMENTS}

We are indebted to Mr B.O. Booth for experimental assistance and to the ILL, Grenoble for providing experimental facilities and support at the High Flux Reactor.

\section{REFERENCES}

1. W. Drost-Hansen, Phys. Chem. Liq., 7 (1978) 243.

2. J. Clifford, in "Water - A Comprehensive Treatise", Vol 5, F. Franks, Ed., p.75. Plenum Press, 1975.

3. D.C. Steytler, J.C. Dore and C.J. Wright, J. Phys. Chem., 87 (1983) 2458.

4. J.E. Bertie and E. Whalley, J. Chem. Phys. 46 (1967) 1271.

5. H. Prask, H. Boutin and S. Yip, J. Chem. Phys., 48 (1968) 3367.

6. J.R. Scherer and R.G. Snyder, J. Chem. Phys., 67 (1977) 4794.

7. A. Rahman and F.H. Stillinger, J. Chem. Phys., 55 (1971) 3336.

8. F.H. Stillinger and A. Rahman, J. Chem. Phys., $\overline{57}$ (1972) 1281.

9. W.S. Benedict, N. Gailar and E.R. Plyler, J. Chem. Phys., 24 (1956) 1139.

10. P.T.T. Wong and E. Whalley, J. Chem. Phys., 62 (1975) 2418.

11. M. Magat and L. Reinisch, Phys. Chem. Liq., $\overline{7}$ (1977) 5.

12. J.D.F. Ramsay and B.O. Booth, J. Chem. Soc., Faraday Trans. 1, 79 (1983) 173.

13. J.D.F. Ramsay and R.M. Richardson, ILL Workshop on "Water at Interfaces" $81 \mathrm{T0555,}$ Grenoble, 1981 .

14. Neutron Research Facilities at the ILL High F1ux Reactor. Ed. B. Maier. 1983.

15. R. Almairac, J.L. Prefaut, M. Galtier, C. Benoit, A. Montaner and H.J. Lauter, Mo1. Cryst. Liq. Cryst. 69 (1981) 177 .

16. F.H. Stillinger, Science, 209 (1980) 451.

17. J. van der E1sken and D.W. Robinson, Spectrochimica Acta, 17 (1961) 1249.

18. H.J. Prask and H. Boutin, J. Chem. Phys., 45 (1966) 3284.

19. See e.g. S.J. Gregg and K.S.W. Sing, "Adsorption Surface Area and Porosity, Academic Press, London, p. 135 et seq. (1967). 